Check for updates

Cite this: RSC Adv., 2017, 7, 43186

Received 29th June 2017

Accepted 29th August 2017

DOI: $10.1039 / c 7 r a 07204 j$

rsc.li/rsc-advances

\section{Effect of composition and macropore percentage on mechanical and in vitro cell proliferation and differentiation properties of 3D printed HA/ $\beta$-TCP scaffolds}

\begin{abstract}
Ningbo Zhao, ${ }^{\text {abc }}$ Yanen Wang, ${ }^{d}$ Lei Qin, ${ }^{e}$ Zhengze Guo ${ }^{e}$ and Dehua Li ${ }^{\star e}$
Alveolar ridge restoration and augmentation is a challenge in dental implantology. 3D printing allows the manufacture of scaffolds with controlled complex structure and adjustable pore size and percentage. $\mathrm{HA} / \beta-\mathrm{TCP}$ is the most commonly used ceramic in 3D printing for its ideal biocompatibility, osteoconductivity, biodegradability, and lack of risk from infection or rejection. However, the effect of composition and macropore percentage $\left(P_{\text {macro }}\right)$ on the mechanical and biological properties of 3D printed HA/ $\beta$-TCP scaffolds is debatable. In this study, HA/ $\beta$-TCP scaffolds with various compositions (weight ratio (wt\%) of $\mathrm{HA}$ varied at $0,20,40,60,80$ and $100 \%$ ) and $P_{\text {macro }}(0 \%, 30 \%$ and $50 \%$ ) were fabricated via 3D printing. The effect of composition and $P_{\text {macro }}$ on the scaffold was investigated. The results showed compressive strength (CS) values, elastic modulus, degradation and biocompatibility in vitro were significantly affected by both the composition and $P_{\text {macro, }}$ which exhibited an interactive effect. Biphasic calcium phosphate ceramics demonstrated higher CS values, elastic modulus, seeding efficiency, cell proliferation and differentiation capability compared to pure HA or pure $\beta$-TCP scaffolds. The degradation of scaffolds decreased as HA wt\% increased or $P_{\text {macro }}$ decreased. In conclusion, scaffolds with $\mathrm{HA}$ wt $\%$ of $40 \%$ and $P_{\text {macro }}$ of $50 \%$ performed optimum cell proliferation, while scaffolds with $\mathrm{HA}$ wt $\%$ of $60 \%$ and $P_{\text {macro }}$ of $30 \%$ exhibited optimum osteogenic differentiation. The results provide some useful insights on applying 3D printed HA/ $\beta$-TCP scaffolds for augmenting absorbed alveolar ridges.
\end{abstract}

\section{Introduction}

Dental implant technology is currently a reliable and wellestablished treatment option to restore an edentulous site resulting from disease, trauma or surgery. ${ }^{1}$ Adequate bone and soft tissue support is essential for successful implant placement. However, absorption of the alveolar ridge is a great challenge in dental implantology. ${ }^{2}$ To restore and augment the absorbed alveolar ridge, various bone grafts, such as autografts, allografts, xenografts, and synthetic bone substitutes as onlay

${ }^{a}$ Key Laboratory of Shaanxi Province for Craniofacial Precision Medicine Research, College of Stomatology, Xi'an Jiaotong University, 98 XiWu Road, Xi'an, Shaanxi, 710004, People's Republic of China

${ }^{b}$ Clinical Research Center of Shaanxi Province for dental and Maxillofacial Disease, College of Stomatology, Xi'an Jiaotong University, 98 XiWu Road, Xi'an, Shaanxi, 710004, People's Republic of China

${ }^{\circ}$ Department of Implant Dentistry, College of Stomatology, Xi'an Jiaotong University, 98 XiWu Road, Xi'an, Shaanxi, 710004, People's Republic of China

${ }^{d}$ The Key Lab of Contemporary Design and Integrated Manufacturing Technology of Ministry of Education, Northwestern Polytechnical University, 127 Youyi West Road, Xi'an 710072, Shaanxi, People's Republic of China

${ }^{e}$ State Key Laboratory of Military Stomatology, Department of Oral Implants, School of Stomatology, Fourth Military Medical University, 145 Changle West Road, Xi'an 710032, Shaanxi, People's Republic of China.E-mail: lidehua@fmmu.edu.cn bone grafts have been tested and used. ${ }^{3,4}$ Though autografts show good histocompatibility and prognosis, they have many disadvantages, including the high cost of bone harvesting, the high morbidity at the donor site and the high absorption rate. ${ }^{3}$ In addition, only limited bone can be collected from patients. ${ }^{5}$ Moreover, the risk of infection or pathogen transfer is the major drawback of allografts and xenografts. ${ }^{4}$ Given these reasons, patients prefer synthetic bone substitutes. ${ }^{6}$ The development and evaluation of synthetic bone substitutes has been the focus of recent studies. ${ }^{3,7}$

The basic requirements of an ideal bone scaffold are good biocompatibility, proper mechanical properties and satisfactory biodegradability. ${ }^{8,9}$ An ideal bone scaffold must allow cells to adhere and induce no local or systematic toxic effects on the host tissue. ${ }^{10}$ The mechanical properties of an ideal bone scaffold have to match those of the host bone. In addition, an ideal bone scaffold should degrade gradually and make space for the new bone to grow-in. ${ }^{9}$ The mechanical properties, biocompatibility and biodegradability of bone scaffold are influenced by various factors, such as composition, porosity, pore size, local $\mathrm{pH}$ value and so on. Hence, it is the key challenge to design and manufacture an ideal bone scaffold in tissue engineering. ${ }^{10}$ 
Bone scaffold can be manufactured by various techniques, such as gas foaming, ${ }^{11}$ freeze drying, ${ }^{12}$ thermally induced phase separation $^{\mathbf{1 3}}$ and so on. In these traditional methods, it is difficult to fabricate scaffold with fully controlled pore size, pore shape, and the interconnectivity. ${ }^{14} 3 \mathrm{D}$ printing, also referred to as additive manufacturing (AM), solid-free form technology (SFF), or rapid prototyping, was first introduced by Charles Hull $^{15}$ in 1986 and was applied to fabricate scaffold with welldefined architecture and customized complex shapes. ${ }^{\mathbf{1 6 , 1 7}} 3 \mathrm{D}$ printing can make up for the limitations of the traditional methods. ${ }^{17-20}$ Various materials can be used to fabricate bone scaffolds by $3 \mathrm{D}$ printing, including biodegradable polymers, ceramics, polymer-ceramic composites and so on. ${ }^{21}$ Hydroxyapatite (HA) is the major inorganic constituent of native bone. ${ }^{22}$ $\beta$-Tricalcium phosphate ( $\beta$-TCP) has biocompatibility, biodegradability and is of special interest as a bone graft material. ${ }^{23}$ In addition, ceramic scaffolds can release calcium ions, which enhance osteoblasts mineralization and bone tissue regeneration. ${ }^{24}$ However, it is acknowledged that HA hardly can be absorbed, while $\beta$-TCP dissolves too fast. ${ }^{25}$ Therefore, biphasic calcium phosphate ceramics (BCPs) with different HA/ $\beta$-TCP weight ratios (wt\%) were developed to adjust the mechanical and biological characteristics of the materials. ${ }^{26}$ BCPs have been the most commonly used bioactive ceramics in 3D printing for their ideal biocompatibility, osteoconductivity, biodegradable, and free from risk of infection or rejection. ${ }^{20,27,28}$

Previous studies have shown that composition and macropore percentage $\left(P_{\text {macro }}\right)$ are two critical factors that affect the mechanical and biological properties of $3 \mathrm{D}$ printed HA/ $\beta$-TCP scaffold. ${ }^{16,27,29}$ Currently, the effect of composition on the compressive strength (CS) values of $3 \mathrm{D}$ printed HA/ $\beta$-TCP scaffolds is debatable. Some researchers claimed that the CS values of HA/ $\beta$-TCP scaffolds firstly increased and then decreased, with rising HA content in the scaffolds. ${ }^{16,19}$ While other researchers reported that as the HA content increased, the CS values decreased. ${ }^{27}$ Surprisingly, another study showed that pure HA or TCP scaffold presented better mechanical properties than BCPs. ${ }^{22}$ The current consensus opinion is that BCPs show better biocompatibility and enhanced bone regeneration capability compared to pure HA or pure $\beta$-TCP scaffolds. And the mostly investigated BCP scaffold is the one with $\mathrm{HA} / \beta-\mathrm{TCP} w \mathrm{t} \%$ of $60: 40$. However, determining the optimum HA/ $\beta$-TCP wt $\%$ of the scaffold to encourage cell growth, proliferation, and promote cell differentiation still provokes controversies. Some researchers reported that the cell viability and proliferation was enhanced on BCPs in comparison with pure HA or pure $\beta$-TCP scaffolds. ${ }^{27}$ While others showed that the cell viability and proliferation was nearly the same on the 3D printed pure HA, pure $\beta$-TCP and various BCPs. ${ }^{29}$ Pore size and porosity of the scaffold are two important factors that can significantly affect fluid exchange, ion delivery, nutrient and cell migration. ${ }^{27}$ Study indicated that, on the one hand, higher porosity can enhance the osteoinductive capacity of scaffold by accelerating the degradation rate. ${ }^{30}$ On the other hand, the CS values may be decreased with the rising porosity. ${ }^{16}$ It is acknowledged that scaffold with higher porosity is beneficial to rapid assimilation and long-term integrity. However, much denser scaffold would be good to mechanical resilience in surgery and stability during the initial integration period. ${ }^{31}$ The optimal porosity of $3 \mathrm{D}$ printed HA/ $\beta$-TCP scaffold fulfilling both mechanical and biological requirements is still unclear, thus, a desirable balanced porosity must be achieved.

Therefore, in this study, we have fabricated HA/ $\beta$-TCP scaffolds with six compositions (wt $\%$ of HA varied at $0,0.20,0.40$, $0.60,0.80$ and 1.00$)$ and three $P_{\text {macro }}(0 \%, 30 \%$ and $50 \%)$ by $3 \mathrm{D}$ printing. The characteristics, total porosity ( $\left.P_{\text {total }}\right)$, CS value, elastic modulus and degradation of the scaffolds were measured. We have evaluated the in vitro biocompatibility of HA/ $\beta$-TCP scaffolds by culturing with rabbit bone marrowderived stem cells (BMSCs), trying to identify the optimal composition and porosity of the scaffold, in order to provide some useful information in applying $3 \mathrm{D}$ printed $\mathrm{HA} / \beta$-TCP scaffold to restore and augment the absorbed alveolar ridge.

\section{Experimental procedures}

\section{Fabrication of scaffolds}

HA and $\beta$-TCP powders were purchased from Kunshan Huaqiao New Materials Co., Ltd., China. HA powder, purity of $0.99, \mathrm{Ca} / \mathrm{P}$ of 1.67, was irregular in shape and the average particle size was $0.06-0.10 \mu \mathrm{m}$. The parameters of $\beta$-TCP powder were as follows: average particle size of $0.10-0.30 \mu \mathrm{m}, \mathrm{Ca} / \mathrm{P}$ of 1.50 , and purity is greater than or equal to 0.98 . The appropriate amount of HA and $\beta$-TCP powders were weighed and mixed thoroughly to prepare the desired composition with HA wt $\%$ of $0,0.20,0.40$, $0.60,0.80$ and 1.00 , respectively. In other words, the scaffold with HA wt\% of 0 was pure $\beta$-TCP scaffold. Scaffold with HA wt $\%$ of 1.00 was pure HA scaffold. And scaffolds with HA wt\% of $0.20,0.40,0.60$ and 0.80 were various BCPs scaffolds. Scaffolds with $P_{\text {macro }}$ of $0,0.30$ and 0.50 were designed in Solidworks CAD software (SolidWorks Corp, USA) and converted to the standard STL. file format. The parameters of designed cylindrical scaffold were as follows: diameter of $10 \mathrm{~mm}$, height of $3 \mathrm{~mm}$ and the pore size of $500 \mu \mathrm{m}$. A ZPrinter ${ }^{\circledR} 250$ printer (ZCorporation Inc., USA; now owned by 3D Systems Inc., USA) was then employed to print constructs using a powder layer thickness of $0.10 \mathrm{~mm}$ and phosphoric acid binder spray of $0.30 \mathrm{~L} \mathrm{~m}^{-2}$. Scaffolds were left to dry for $2 \mathrm{~h}$ before being removed from the build bed as recommended by the manufacturer. De-powdering was performed using compressed air directed through a syringe needle. After printing, the scaffolds were post-treated by dipping in phosphoric acid (wt\% of 0.1 ) to improve surface binding and then washed in deionized water to remove residual acidity. Prior to biological experiments, the scaffolds were neutralized to $\mathrm{pH} 7$ with $\mathrm{NaOH}$ and sterilized by gamma radiation.

\section{Micro-CT imaging}

Scaffolds with 3 different $P_{\text {macro }}$ were placed on the base of the high-resolution micro-CT scanner (Inveon, Siemens, Germany). The scanning parameters were as follows: $80 \mathrm{kV}, 500 \mu \mathrm{A}$ with a $2000 \mathrm{~ms}$ exposure time. The resolution was set at $27.82 \mu \mathrm{m}$ and the rotation step of 0.67 . The scaffolds were reconstructed 
three-dimensionally using software Mimics 10.01 (Materialise, Leuven, Belgium).

\section{X-ray diffraction (XRD) analysis}

The scaffolds were milled into fine powder and the phase composition was analyzed by XRD. XRD was carried out using an X-ray diffractometer (X'Pert PRO, PANalytical, the Netherlands) with $\mathrm{Cu}-\mathrm{K} \alpha(\lambda=0.15 \mathrm{~nm})$ incident radiation. In brief, scaffolds were powdered using a mortar and pestle. The electrical voltage and current were $40 \mathrm{kV}$ and $20 \mathrm{~mA}$, respectively. Data collection was performed in the range of $2 \theta=20-40^{\circ}$ with a step size of $0.03^{\circ}$.

\section{Porosity calculation}

The $P_{\text {total }}$ of the scaffolds was indirectly evaluated by the method proposed by Guo et al. ${ }^{19}$ Briefly, $P_{\text {total }}$ of a scaffold was calculated according to the following equation

$$
P_{\text {total }}=\left(1-d_{\text {apparent }} / d_{\mathrm{BCP}}\right) \times 100 \%
$$

$d_{\text {apparent }}$, the apparent density of the dried scaffold, was calculated by the mass of the scaffold and its geometric volume. $d_{\mathrm{BCP}}$ is the theoretical density of the BCP scaffold calculated from the following equation

$$
d_{\mathrm{BCP}}=\left(d_{\mathrm{HA}} \times d_{\mathrm{TCP}}\right) /\left(\delta \times d_{\mathrm{TCP}}+(1-\delta) \times d_{\mathrm{HA}}\right)
$$

where $\delta$ is the weight ratio of HA in the BCP scaffold. Theoretical densities of HA and $\beta$-TCP $\left(d_{\mathrm{TCP}}\right)$ are $3.16 \mathrm{~g} \mathrm{~cm}^{-3}$ and $3.07 \mathrm{~g} \mathrm{~cm}^{-3}$, respectively. ${ }^{32}$

\section{CS value and elastic modulus test}

CS values and elastic modulus of all scaffolds were measured using a computer-controlled Universal Testing Machine (Instron 5567, Instron, USA). The cross-head speed was set to $0.50 \mathrm{~mm} \mathrm{~min}^{-1}$. A total of 5 scaffolds of each group were tested under the same conditions.

\section{Degradation in vitro}

The degradation of the scaffolds was determined by the mass loss. In brief, the mass $\left(M_{1}\right)$ of the HA/ $\beta$-TCP scaffolds $(n=$ 5 /group) were measured. Afterwards, they were immersed in simulated body fluid (SBF) and placed in a $37{ }^{\circ} \mathrm{C}$ incubator. After 12 weeks in SBF, the scaffolds were taken out and lyophilized to measure mass again $\left(M_{2}\right)$. The mass loss was calculated using the following equation

$$
\text { The mass loss }(\%)=\left(M_{1}-M_{2}\right) / M_{1} \times 100 \%
$$

The images showing scaffolds after degradation were taken. And the XRD was carried out as mentioned above.

\section{Isolation and culture of rabbit BMSCs}

Rabbits were purchased from the Experimental Animal Center of the Fourth Military Medical University [Animal License No.
SCXK-(Militar) 2012-007]. They were sacrificed by overdose injection of sodium pentobarbital. Bone marrow (BM) was harvested from the tibia and femur condyle under aseptic conditions. The BM-phosphate-buffered saline (PBS) mixture $(10 \mathrm{~mL})$ was centrifuged for $8 \mathrm{~min}$ at $1000 \mathrm{rpm}$ (L500, XiangYi, China) and the supernatant was removed. Pellets were suspended in cell culture medium that contained $\alpha$-minimum essential media ( $\alpha$-MEM) (Gibco, USA), 10\% fetal bovine serum (FBS) (Gibco, USA), and penicillin/streptomycin/amphotericin B (Sangon Biotech, China) and centrifuged again. Then the cell sediment was resuspended in $10 \mathrm{~mL}$ cell culture medium and cultured at $37^{\circ} \mathrm{C}$ in a humidified atmosphere of 95\% air and 5\% $\mathrm{CO}_{2}$. Adherent BMSCs were obtained by complete medium changes after 2 days. ${ }^{35}$ Following this the culture medium was changed every 3 days. After reaching about $85 \%$ confluence, BMSCs were trypsinized with $0.25 \%$ trypsin and counted to yield the primary passage (P0). Cells of passage 4 were used for all the following experiments. All animal experiments were performed and followed the guidelines of the Experimental Animal Center in Fourth Military Medical University. All animal experimental procedures were approved by the Laboratory Animal Care \& Welfare Committee, School of Stomatology, Fourth Military Medical University.

\section{Osteogenic induction and alizarin red staining}

BMSCs were seeded in 6-well plates at a density of $1 \times 10^{5}$ cells per well. Osteogenic medium was $\alpha$-MEM supplemented with 5\% FBS, $0.10 \mathrm{mM}$ dexamethasone (Sigma, USA), $10 \mathrm{mM}$ $\beta$-glycerophosphate (Alfa Aesar, USA), $50 \mathrm{mM}$ L-ascorbic acid (Sigma, USA), and 1\% antibiotic/antimycotic. The osteogenic differentiation medium was changed every 3 days. Control group wells were BMSCs cultured in the regular $\alpha$-MEM medium. Mineralization was determined by Alizarin Red (Sigma, USA) staining after 28 days. The calcium deposits were observed with an inverted microscope (CKX41, Olympus, Japan).

\section{Seeding efficiency}

The scaffolds were placed in 24-well plates not treated for tissue culture. A drop of $50 \mu \mathrm{L}$ of the cell suspension (containing $1 \times$ $10^{5}$ cells) was seeded on the top surface of each scaffold in each well. After a period of $3 \mathrm{~h} 1 \mathrm{~mL}$ medium was additionally added to each well. The scaffolds were left under standard cell culture conditions for $12 \mathrm{~h}$ to give the cells enough time to adhere to and establish themselves in the scaffolds. Afterwards, the scaffolds were removed and the remaining cells in the wells were digested with $0.25 \%$ trypsin (Sigma, USA) and counted using a cell counting machine TC 10 (Bio-Rad, USA). The seeding efficiency was calculated according to the following equation

Seeding efficiency $(\%)=($ cells added to scaffold - cells in wells $) /$ cells added to scaffold $\times 100 \%$. 
The values reported are the averages of at least 3 scaffolds of each group.

\section{Scanning electron microscopic (SEM) analysis}

The dimensions of macropores and micropores in the printed scaffolds were measured. The cell-seeded scaffolds $\left(1 \times 10^{5}\right.$ cells per scaffold per well in 24-well plate) were washed with PBS and fixed in $2.5 \%$ glutaraldehyde. Following the dehydration through a series of graded ethanol, the scaffolds were dried with freeze dryer (es-2030, HITACHI, Japan). Subsequently, the printed scaffolds and the cell-seeded scaffolds were sputtered with gold (e-1045, HITACHI, Japan). The surface topography of the printed scaffolds and the cell attachment on the cell-seeded scaffolds was analyzed by a scanning electron microscope (S-4800, HITACHI, Japan).

\section{Cell proliferation}

Cell proliferation was continuously monitored using Cell Counting Kit-8 (CCK-8, MP biomedicals, USA) according to the manufacturer's instruction. Briefly, $1 \times 10^{5}$ cells per well were seeded onto each scaffold and cultured with regular $\alpha$-MEM medium in 24-well plates. On Day 1, Day 4 and Day 7, the culture medium was changed to fresh $\alpha$-MEM medium with $10 \%$ CCK- 8 solution. The cell-seeded scaffolds were incubated with CCK- 8 agent for $1 \mathrm{~h}$. Then the medium was transferred into a 96-well plate and the absorbance was measured at $450 \mathrm{~nm}$ using a microplate reader PowerWave XS (Bio-Tek, USA). Cells cultured in wells without scaffold and medium without cells were set as negative and blank control, respectively.

\section{Real-time reverse-transcription polymerase chain reaction (RT-PCR)}

The messenger ribose nucleic acid (mRNA) expression of cell lineage-specific genes was determined by real-time RT-PCR analysis. The experimental procedure was described as follows. Briefly, total cellular RNA was harvested from cultured BMSCs (the control group) and BMSCs seeded on scaffolds (the test group) (a density of $1 \times 10^{5}$ cells per scaffold per well in 24-well plate) undergoing 14 days of osteogenic differentiation using the Trizol reagent (Invitrogen, USA), according to the manufacturer's protocol. RNA concentration and quality were quantified by an Epoch microplate reader (Bio-Tek, USA). cDNA was synthesized by reverse transcription from $20 \mu \mathrm{L}$ of total RNA using PrimeScript RT regent Kit (Takara, Japan) under the conditions of $15 \mathrm{~min}$ at $37^{\circ} \mathrm{C}$, followed by $5 \mathrm{~s}$ at $85^{\circ} \mathrm{C}$ on a reverse transcription machine (T Gradient, Biometra, Germany). Real-time RT-PCR reactions containing $5 \mu \mathrm{L}$ of $2 \times$ SYBR Premix Ex Taq ${ }^{\mathrm{TM}} \mathrm{II}$ (Takara, Japan), $3.20 \mu \mathrm{L}$ of RNAse free water, $0.40 \mu \mathrm{L}$ of $0.40 \mu \mathrm{M}$ forward primer and reverse primer, respectively, and $1 \mu \mathrm{L}$ of cDNA in a total volume of $10 \mu \mathrm{L}$, were run on a real-time PCR machine (C-1000 Thermal cycler, Bio-Rad, USA). Specific primers of $\beta$-actin, a housekeeping gene acted as internal control, alkaline phosphatase (ALP), runt-related transcription factor 2 (RUNX-2) and osteocalcin (OCN) gene for osteogenic differentiation, were designed using Oligo 7.0 software (Molecular Biology Insights Inc., USA). Their sequences and product sizes were listed in Table
Table 1 The sequences and product sizes of the genes used in realtime RT-PCR ( $F$ and $R$ indicate forward primer and reverse primer, respectively)

\begin{tabular}{llll}
\hline Gene & Primer & Primer sequences $\left(5^{\prime} \rightarrow 3^{\prime}\right)$ & $\begin{array}{l}\text { Product size } \\
(\mathrm{bp})\end{array}$ \\
\hline ALP & $\mathrm{F}$ & TGGACCTCGTGGACATCTG & 80 \\
& $\mathrm{R}$ & CAGGAGTTCAGTGCGGTTC & \\
RUNX-2 & $\mathrm{F}$ & GCAGTTCCCAAGCATTTCATC & 81 \\
& $\mathrm{R}$ & GTGTAAGTAAAGGTGGCTGGATA & \\
OCN & $\mathrm{F}$ & GAAGCCCAGCGGTGCA & 70 \\
& $\mathrm{R}$ & CACTACCTCGCTGCCCTCC & \\
$\beta$-Actin & $\mathrm{F}$ & GCGACCTCACCGACTACCT & 136 \\
& $\mathrm{R}$ & GCCATCTCGTTCTCGAAGTC & \\
\hline
\end{tabular}

1. All the primers were synthesized by the same manufacturer (Sangon Biotech, China). Real-time RT-PCR reactions were performed using the parameters as follows: 3 min of denaturation at $95^{\circ} \mathrm{C}$, followed by 40 rounds of $10 \mathrm{~s}$ of annealing at $95^{\circ} \mathrm{C}, 30 \mathrm{~s}$ of extension at $60^{\circ} \mathrm{C}$. Data were collected as threshold cycle $\left(C_{\mathrm{t}}\right)$ value. The relative mRNA expressions of ALP, RUNX-2 and OCN were normalized to internal $\beta$-actin expression, and calculated using the $2^{-\Delta \Delta C_{t}}$ method. Each sample was performed in triplicate to ensure the accuracy of the data.

\section{Statistical analysis}

All data were expressed as mean \pm standard deviation (SD). One-way analysis of variance (ANOVA) was applied to compare two more means. The main effects of composition, $P_{\text {macro }}$, as well as the interaction effects between them were evaluated by factorial analysis. Multiple comparison between groups was performed using least significant difference (LSD) method if the equality of variances could be assumed. On the contrary, if the equality of variances could not be assumed, the post hoc multiple comparison test with Games-Howell was performed. Analyses were performed using SPSS 16.0 (SPSS Inc, Chicago, Illinois). A $P$ value $<0.05$ was considered statistically significant.

\section{Results}

\section{Characteristics of 3D printed HA/ $\beta$-TCP scaffolds}

The cylindrical scaffolds with diameter of $10 \mathrm{~mm}$, height of $3 \mathrm{~mm}$, macropore size of $500 \mu \mathrm{m}$ and $P_{\text {macro }}$ of $0 \%, 30 \%$ and $50 \%$ were designed using Solidworks CAD software (Fig. 1A). Photographs of 3D printed scaffolds are demonstrated in Fig. 1B. Micro-CT and $3 \mathrm{D}$ reconstruction images showed layers of powders, macropores and struts of the scaffolds (Fig. 1C). The dimension of macropores was about $500 \mu \mathrm{m}$ and the distribution of macropores was well matched to what was designed. The surface morphology of the 3D printed scaffolds was characterized using SEM. All the scaffolds exhibited a roughened topography on particles. Representative SEM images of scaffolds with HA wt $\%$ of $60 \%, P_{\text {macro }}$ of $0 \%, 30 \%$ and $50 \%$, respectively, are shown in Fig. 2. The macropore dimension was $502.47 \pm 5.13 \mu \mathrm{m}$, which was in accordance with the designed macropore and confirmed the accuracy of 3D printing. By analyzing the high-magnification SEM images, it can 


\section{A}
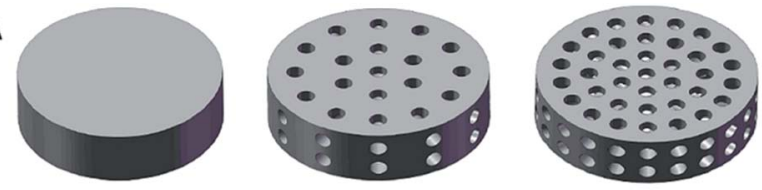

B
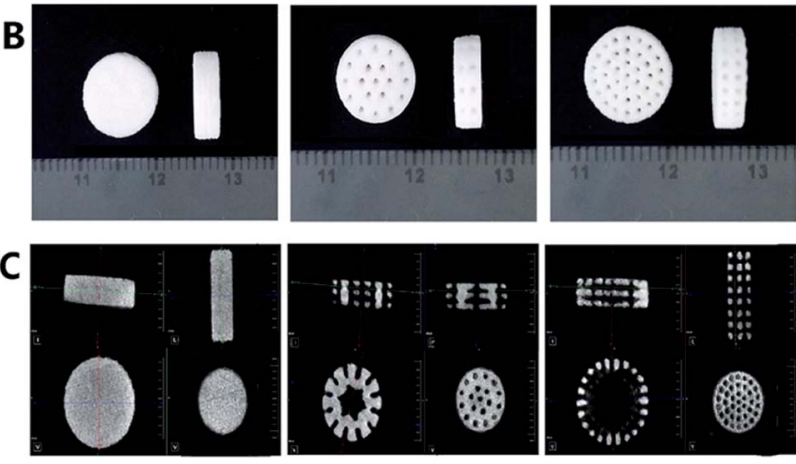

Fig. 1 Characteristics of 3D printed HA/ $\beta$-TCP scaffolds. (A) Designed scaffolds with $P_{\text {macro }}$ of $0 \%, 30 \%$ and $50 \%$ using Solidworks CAD software. (B) Photographs of 3D printed scaffolds. (C) Micro-CT and $3 \mathrm{D}$ reconstruction images of printed scaffolds.

be seen that micropores existed in the microstructure of scaffolds. It ranged between 10 to $30 \mu \mathrm{m}$ (Fig. 2B).

The XRD analysis of the $3 \mathrm{D}$ printed HA/ $\beta$-TCP scaffolds are shown in Fig. 3A. The XRD patterns of pure HA and pure $\beta$-TCP scaffolds, which are the two staring powders, matched well with those of standard phase-pure HA (XRD JCPDS file No. 09-0432) and $\beta$-TCP (No. 09-0169), respectively. The varying intensities and different peaks showed the gradual variance in phase composition of scaffolds with different HA/ $\beta$-TCP wt $\%$. The $P_{\text {total }}$ of the scaffolds with different composition and $P_{\text {macro }}$ are shown in Fig. 3B. The $P_{\text {total }}$ of scaffolds with $P_{\text {macro }}$ of $0 \%, 30 \%$ and $50 \%$ were $15.13-$ $18.88 \%, 38.23-42.64 \%$ and $51.16-56.97 \%$, respectively, which were significantly higher than those with the designed $P_{\text {macro, }}$, respectively $(P<0.05)$. For scaffolds of a given $P_{\text {macro, }}$ however,
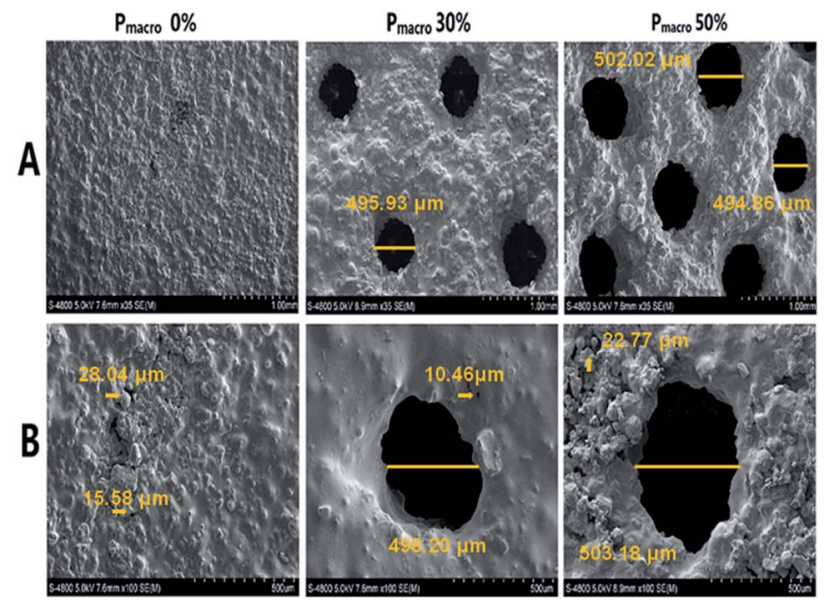

Fig. 2 Representative SEM images of scaffolds with HA wt\% of $60 \%$, $P_{\text {macro }}$ of $0 \%, 30 \%$ and $50 \%$, respectively. (A) Low-magnification (magnification, $\times 35)$. (B) High-magnification (magnification, $\times 100$ ). Arrows point to micropores.
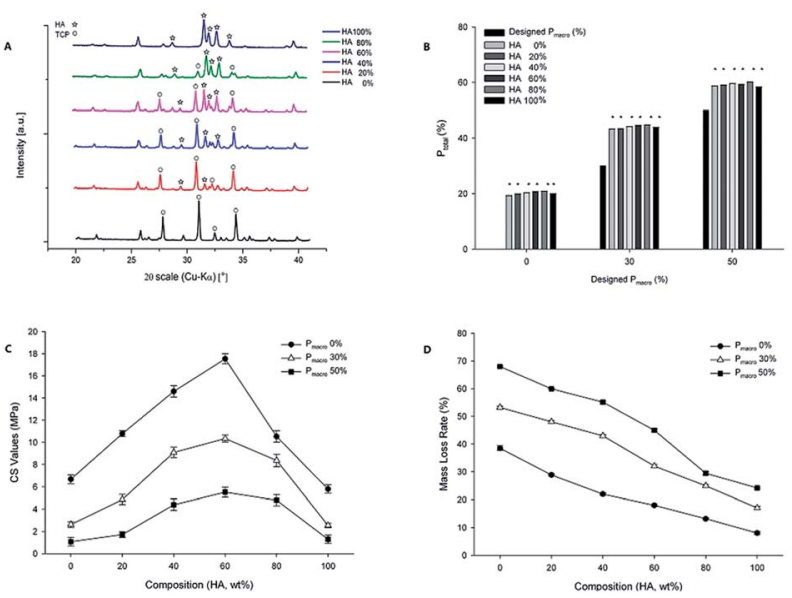

Fig. 3 XRD analysis, $P_{\text {total }}, C S$ values and elastic modulus of 3D printed HA/ $\beta$-TCP scaffolds. (A) XRD analysis from pure HA (top) to pure $\beta$-TCP (bottom). (B) $P_{\text {total }}$ of 3D printed scaffolds. $* P<0.05$. (C) CS values. (D) Elastic modulus

there was no significant differences among the $P_{\text {total }}$ of BCPs scaffolds with HA wt $\%$ of $40 \%, 60 \%, 80 \%$, respectively $(P>0.05)$.

\section{CS values and elastic modulus of 3 D printed HA/ $\beta$-TCP scaffolds}

The composition and $P_{\text {macro }}$ had an interactive effect on the CS values (Fig. 3C, $F=46.09, P=0.00$ ). For scaffolds of a given $P_{\text {macro, }}$, the composition significantly affected the CS values, which firstly increased and then decreased as the $\mathrm{HA} \mathrm{wt} \%$ increased $(F=578.50, P=0.00)$. The transition point occurred at $\mathrm{HA} w \mathrm{wt} \%$ of $60 \%$. At this point, the CS values reached the maximum $17.54 \mathrm{MPa}$ with the $P_{\text {macro }}$ of $0 \%$. The CS values of scaffolds with HA wt $\%$ of $40 \%, 60 \%, 80 \%$ were higher than those of pure HA and pure $\beta$-TCP, respectively $(P<0.05)$. However, for scaffolds of a given $P_{\text {macro }}$, there were no significant differences among the CS values of BCPs scaffolds with HA wt $\%$ of $40 \%, 60 \%, 80 \%(P>0.05)$. For scaffolds of a given HA wt $\%$, the CS values among scaffolds with different $P_{\text {macro }}$ had significant differences $(P<0.05)$. The higher the $P_{\text {macro }}$ was, the lower the CS value was.

The elastic modulus of the 3D printed HA/ $\beta$-TCP scaffolds was significantly affected by both the composition and the $P_{\text {macro, }}$, which showed an interactive effect (Fig. 3D, $F=2.48, P=$ 0.02 ). For scaffolds of a given $P_{\text {macro, }}$, the elastic modulus firstly increased and then decreased. However, there were no significant differences among scaffolds with various $\mathrm{HA}$ wt $\%$ with respect to the elastic modulus $(P>0.05)$. The elastic modulus of BCPs were higher than those of pure HA or pure $\beta$-TCP, respectively. However, for scaffolds with $P_{\text {macro }}$ of $50 \%$, the elastic modulus of scaffold with HA wt $\%$ of $20 \%$ was lower than that of pure HA. For scaffolds of a given HA wt\%, the elastic modulus among scaffolds with different $P_{\text {macro }}$ had significant differences $(P<0.05)$. The lower the $P_{\text {macro }}$ was, the higher the elastic modulus was. The scaffolds with $\mathrm{HA}$ wt $\%$ of $60 \%$ and $P_{\text {macro }}$ of $0 \%$ had the highest elastic modulus, which was $1.84 \pm$ $0.04 \mathrm{GPa}$. 


\section{Degradation of 3D printed HA/ $\beta$-TCP scaffolds}

Representative images of scaffolds soaked in SBF for 12 weeks were showed in Fig. $4 \mathrm{~A}$. It can be seen that HA/ $\beta$-TCP scaffolds did not change significantly. However, the mass loss of HA/ $\beta$-TCP scaffolds was significantly affected by both the composition and the $P_{\text {macro }}$, which showed an interactive effect (Fig. $4 \mathrm{~B}, F=366.45$, $P=0.00)$. For scaffolds of a given $P_{\text {macro, }}$, the degradation decreased in the following order: pure $\beta$-TCP $>$ BCPs $>$ pure HA. The degradation decreased as the HA wt $\%$ increased. For scaffolds of a given $\mathrm{HA} w \mathrm{t} \%$, the degradation among scaffolds with different $P_{\text {macro }}$ had significant differences $(P<0.05)$. The higher the $P_{\text {macro }}$ was, the higher the degradation was.

Compared to the XRD patterns of HA/ $\beta$-TCP scaffolds before soaking, it can be seen that the phase composition of the scaffolds did not significantly change after soaking in SBF (Fig. 4C). However, hydroxy-carbonate-apatite (HCA) was found in the XRD patterns of HA/ $\beta$-TCP scaffolds after soaking.

\section{Cell culture and osteogenic induction}

After cells were isolated and seeded in culture flasks many RBCs were observed under microscopy (Fig. 5A, D0). At Day 3, most BMSCs attached to cell culture flask had spindle morphology, with some were triangular or irregular shaped, and they were radially distributed (Fig. 5A, D3). At Day 5, BMSCs grew in vortex pattern and reached about $85 \%$ confluence (Fig. 5A, D5).

Being cultured in osteogenic induction medium, cell morphology changed from spindle to stellate- or irregularshaped. Cells grew in multiple layers. Under cultured for 4 weeks, BMSCs formed distinct mineralized nodules stained by Alizarin Red staining (Fig. 5B, induced). In the control group, no mineralized nodules were detected following Alizarin Red staining (Fig. 5B, uninduced). The relative mRNA expressions of ALP, RUNX-2 and OCN were shown in Fig. 5C. The osteogenic induced cells had significantly higher mRNA expressions compared to those of uninduced cells $(P<0.05)$.

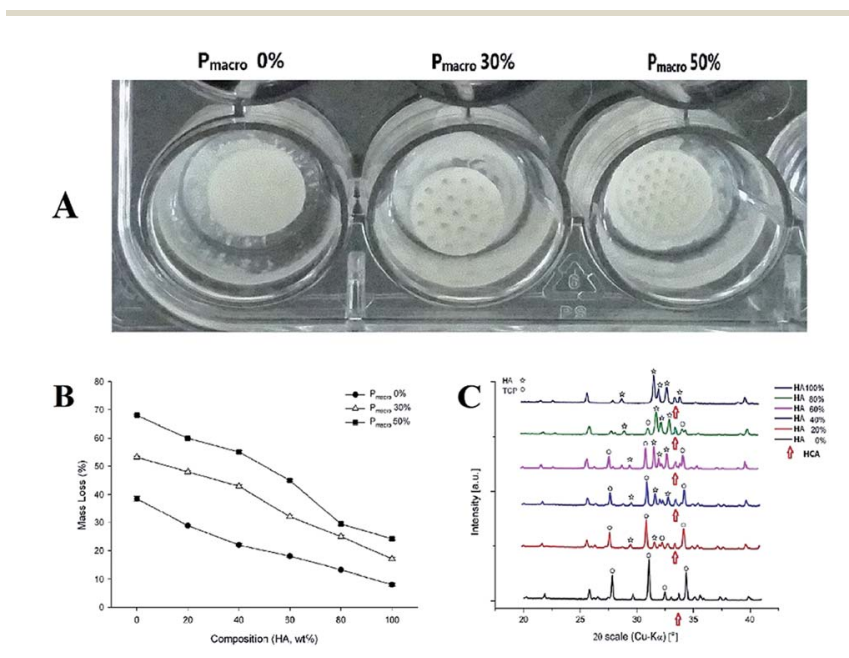

Fig. 4 The degradation of HA/ $\beta-$ TCP scaffolds in vitro. (A) Representative images of scaffolds with $\mathrm{HA}$ wt $\%$ of $60 \%, P_{\text {macro }}$ of $0 \%, 30 \%$ and $50 \%$ after degradation, respectively. (B) Mass loss of scaffolds after 12 weeks in SBF. (C) XRD analysis of scaffolds after degradation.
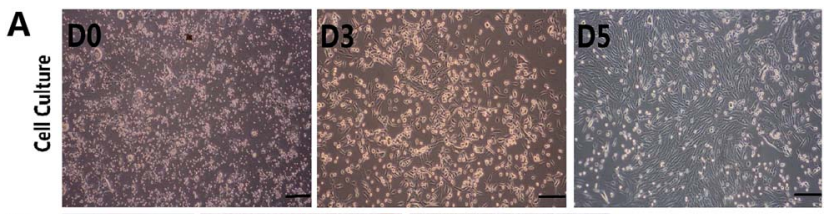

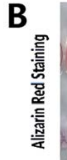
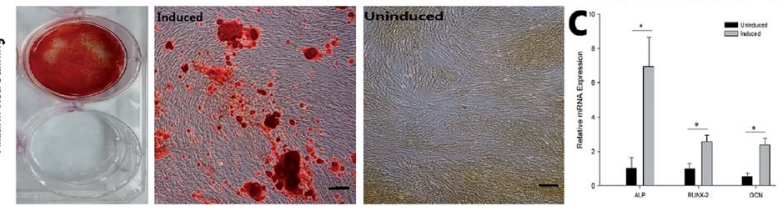

Fig. 5 Cell culture and osteogenic induction of rabbit BMSCs. (Scale bars $=100 \mu \mathrm{m}$ ). (A) Primary rabbit BMSCs cultured on Day 0, Day 3 and Day 5. (B) Alizarin red staining of rabbit BMSCs. From left to right: macroscopic observation of osteogenic induced and uninduced BMSCs; osteogenic induced and uninduced BMSCs (the last two images were got with inverted phase contrast microscope). (C) Relative mRNA expressions of typical osteogenic markers (ALP, RUNX-2 and $\mathrm{OCN}$ ) of osteogenic induced and uninduced rabbit BMSCs. $* P<$ 0.05 .

\section{Cell attachment on scaffolds}

The representative SEM images showed BMSCs attached and spread on HA/ $\beta$-TCP scaffolds with $P_{\text {macro }}$ of $30 \%$, and HA wt $\%$ of $0 \%, 20 \%, 40 \%, 60 \%, 80 \%$ and $100 \%$, respectively (Fig. $6 \mathrm{~A}$ to $\mathrm{F}$, respectively). The seeded BMSCs shaped polygon, spindle or oval. They spread fully on the scaffold surface and established cell-cell interconnections. The morphology and distribution of cells were not affected by the HA/ $\beta$-TCP wt $\%$. These SEM images confirmed the biocompatibility of the 3D printed HA/ $\beta$-TCP scaffolds.

\section{Seeding efficiency}

The composition and $P_{\text {macro }}$ both significantly affected the seeding efficiency. They also had an interactive effect on the seeding efficiency (Fig. 7A, $F=6.89, P=0.00$ ). For scaffolds of
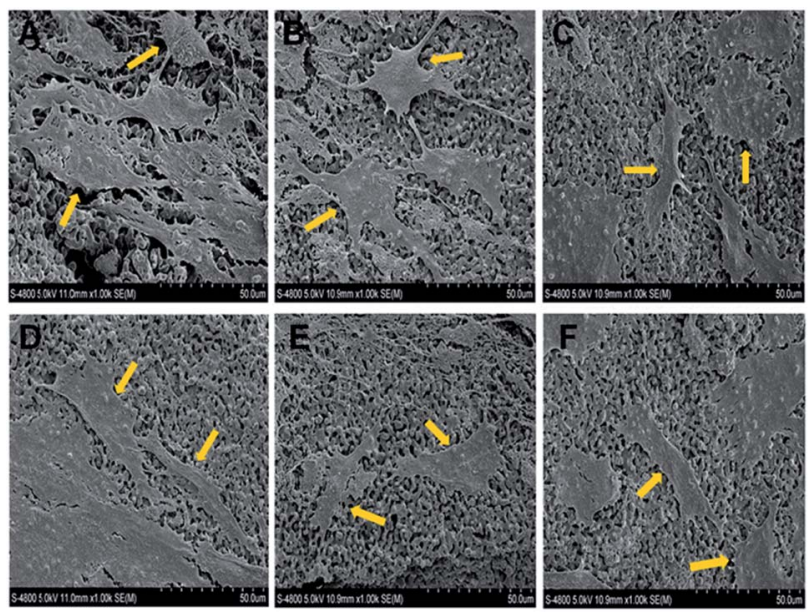

Fig. 6 Representative SEM images of cell attachment on the 3D printed HA/ $\beta$-TCP scaffolds with $P_{\text {macro }}$ of $30 \%$, HA wt $\%$ of $0 \%, 20 \%$, $40 \%, 60 \%, 80 \%$ and $100 \%$, respectively (magnification, $\times 1000$ ). Arrows indicate the seeded BMSCs. (A) to (F) Refer to scaffolds with $P_{\text {macro }}$ of $30 \%$, HA wt $\%$ of $0 \%, 20 \%, 40 \%, 60 \%, 80 \%$ and $100 \%$, respectively. 
a given $P_{\text {macro }}$, the seeding efficiency of scaffolds with HA wt $\%$ of $60 \%$ was higher than those of pure HA and pure $\beta$-TCP, respectively, which also showed significant differences $(P<$ $0.05)$. The scaffolds with HA wt $\%$ of $40 \%$ and $P_{\text {macro }}$ of $50 \%$ had the highest seeding efficiency, which was $96.33 \%$. However, no significant differences in seeding efficiency were observed with respect to various BCPs $(P>0.05)$. For scaffolds of a given HA wt $\%$, the seeding efficiency among scaffolds with different $P_{\text {macro }}$ showed significant differences $(P<0.05)$. The seeding efficiency increased as the $P_{\text {macro }}$ increased.

\section{Cell proliferation}

On Day 1, Day 4 and Day 7, the cell proliferation on each scaffold was significantly higher as the time prolonged (Fig. 7B, $P<$ 0.05). The cell proliferation was significantly affected by both the composition and the $P_{\text {macro }}$, which showed an interactive effect at each time point (Fig. 7B, $P=0.00$ ), respectively.

For scaffolds of a given $P_{\text {macro }}$, on Day 1 , the cell proliferation on scaffolds with $\mathrm{HA}$ wt $\%$ of $40 \%, 60 \%, 80 \%$ were higher than those on pure HA and pure $\beta$-TCP, respectively, which showed significant differences $(P<0.05)$. On Day 4 and Day 7 , the cell proliferation on scaffolds with HA wt $\%$ of $40 \%$ was significantly higher than those on pure $\beta$-TCP $(P<0.05)$. And the cell proliferation on scaffolds with HA wt $\%$ of $40 \%, 60 \%, 80 \%$ were significantly higher than those on pure HA $(P<0.05)$. However, there was no significant differences among the cell proliferation on BCPs at each time point $(P>0.05)$.

For scaffolds of a given HA wt\%, the higher the $P_{\text {macro }}$ was, the higher the cell proliferation was. On Day 1, the cell proliferation was significantly lower on scaffolds with $P_{\text {macro }}$ of $0 \%$ than on those with $P_{\text {macro }}$ of $30 \%$ and $50 \%$, respectively $(P<$ 0.05). However, no significant difference in cell proliferation was observed between scaffolds with $P_{\text {macro }}$ of $30 \%$ and $50 \%(P>$ 0.05). On Day 4 and Day 7, the cell proliferation among scaffolds with different $P_{\text {macro }}$ showed significant differences $(P<0.05)$. In conclusion, the cell proliferation was the highest on scaffold with HA wt $\%$ of $40 \%$ and $P_{\text {macro }}$ of $50 \%$ at each time point. The cell proliferation on each scaffold was lower than that of the negative control group on Day 1, Day 4 and Day 7, respectively. However, there was no significant difference with respect to the
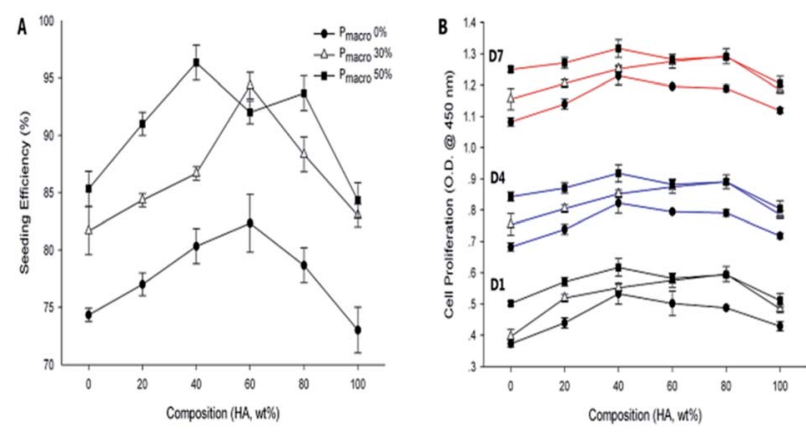

Fig. 7 Seeding efficiency and cell proliferation of 3D printed $H A / \beta-$ TCP scaffolds. (A) Seeding efficiency. (B) Cell proliferation on Day 1 , Day 4 and Day 7. cell proliferation between the scaffold with HA wt $\%$ of $40 \%$ and $P_{\text {macro }}$ of $50 \%$ and the negative control group $(P>0.05)$.

\section{Gene expressions of typical osteogenic markers}

The mRNA expressions of typical osteogenic markers, ALP, RUNX-2 and OCN, were detected by real-time RT-PCR. The ALP, RUNX-2 and OCN mRNA expressions were significantly affected by both the composition and the $P_{\text {macro }}$ (Fig. $8, P<0.05$ ). Moreover, composition and $P_{\text {macro }}$ had an interactive effect on ALP and RUNX-2 mRNA expression $(P<0.05)$.
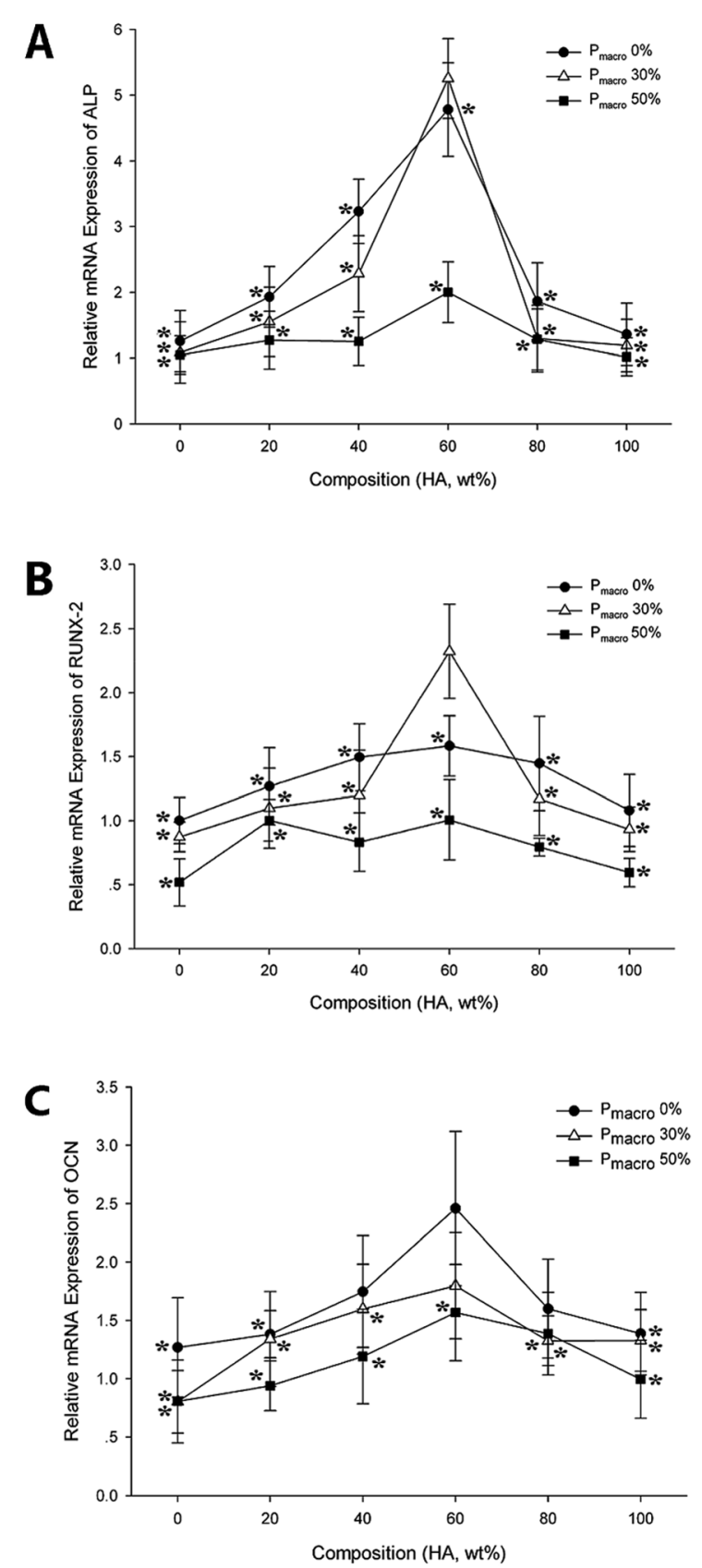

Fig. 8 Relative mRNA expressions of typical osteogenic markers on $3 \mathrm{D}$ printed HA/ $\beta$-TCP scaffolds. ${ }^{*} P<0.05$. (A) Relative mRNA expressions of ALP. (B) Relative mRNA expressions of RUNX-2. (C) Relative mRNA expressions of OCN. 
For scaffolds of a given $P_{\text {macro }}$, ALP mRNA expression on scaffold with HA wt $\%$ of $60 \%$ was significantly higher than those on pure HA, pure $\beta$-TCP, and scaffolds with HA wt $\%$ of $20 \%$ and $80 \%$, respectively $(P<0.05)$. RUNX-2 and OCN mRNA expressions on scaffolds with HA wt $\%$ of $60 \%$ was significantly higher than those on pure $\beta$-TCP scaffolds $(P<0.05)$. However, there were no significant differences among RUNX-2 and OCN mRNA expressions on various BCPs, respectively $(P>0.05)$.

For scaffolds of a given HA wt\%, ALP and OCN mRNA expressions on scaffolds with $P_{\text {macro }}$ of $0 \%$ were significantly higher than on those with $P_{\text {macro }}$ of $50 \%(P<0.05)$. RUNX-2 mRNA expressions on scaffolds with $P_{\text {macro }}$ of $0 \%$ and $30 \%$ were significantly higher than on those with $P_{\text {macro }}$ of $50 \%$, respectively $(P<0.05)$. In conclusion, maximum ALP and RUNX2 mRNA expressions were detected on scaffolds with HA wt $\%$ of $60 \%$ and $P_{\text {macro }}$ of $30 \%$. The scaffolds with HA wt $\%$ of $60 \%$ and $P_{\text {macro }}$ of $0 \%$ showed the highest OCN mRNA expression.

The ALP and RUNX-2 mRNA expressions of BMSCs seeded on scaffolds were lower than those of the control group, respectively. However, ALP and RUNX-2 mRNA expressions on scaffold with HA wt\% of $60 \%$ and $P_{\text {macro }}$ of $30 \%$ showed no significant differences with those of the control group $(P=0.13$, $P=0.83$, respectively). With respect to the OCN mRNA expression, there were no significant differences among scaffolds with HA wt $\%$ of $40 \%, 80 \%$, and $P_{\text {macro }}$ of $0 \%$ and the control group, respectively ( $P=0.28, P=0.13$, respectively). In addition, OCN mRNA expression on scaffolds with HA wt $\%$ of $60 \%$, and $P_{\text {macro }}$ of $0 \%$ and $30 \%$, showed no significant differences with that of the control group $(P=0.83, P=0.28$, respectively). Interestingly, the OCN mRNA expression on the scaffold with HA wt $\%$ of $60 \%$ and $P_{\text {macro }}$ of $0 \%$ was higher than that of the control group.

\section{Discussion}

\section{Characteristics of 3D printed HA/ $\beta$-TCP scaffolds}

In the present study, we manufactured HA/ $\beta$-TCP scaffolds with different compositions and $P_{\text {macro }}$ using 3 D printing. The XRD patterns showed that the phase composition of the scaffolds changed with the altering of HA wt $\%$. The peak patterns of pure HA and $\beta$-TCP scaffolds confirmed the phase-purity of the printed scaffolds, respectively. The intensities varied and the peaks differed in BCPs as the HA wt\% changed. Apparently, the $P_{\text {total }}$ was significantly higher than the designed $P_{\text {macro }}$. It is because that the $P_{\text {total }}$ is consisted of two parts, the designed macropore and the micropore, which is the tiny gap between the powder particles. According to SEM images, the dimensions of micropore were between 10 to $30 \mu \mathrm{m}$ due to the relatively small space between the particles. It was in agreement with the report that the inter agglomeration pores of $3 \mathrm{D}$ printed components are generally ranged from 1 to $100 \mu \mathrm{m} \cdot{ }^{33}$ According to the results of SEM and micro-CT analysis, HA/ $\beta$-TCP scaffolds with high accuracy of pore size, pore distribution and pore interconnectivity can be fabricated by $3 \mathrm{D}$ printing.

Micropores of the bone scaffold are important, which were not only necessary for excellent osteoinductivity of BCP materials but also promoted the absorption of bone substitute in vivo. ${ }^{34,35}$ Macropore size and porosity can significantly influence the mechanical properties, biocompatibility and biodegradability of a would-be bone scaffold, through affecting fluid exchange, ion delivery, nutrient and cell migration. ${ }^{36,37}$ However, there is a controversy in deciding the optimum macropore diameter and $P_{\text {macro }}$ of the bone scaffold. ${ }^{23,36-38}$ Some authors reported pore sizes in the range of 200 to $350 \mu \mathrm{m}$ were optimum for bone tissue ingrowth. ${ }^{36}$ While others claimed that bone ingrowth was most successful when macropores were within the range of 200 to $900 \mu \mathrm{m} .^{23,35,37}$ Furthermore, some others insisted that ideal pore size and porosity of the $3 \mathrm{D}$ printed scaffold was 500 to $1000 \mu \mathrm{m}$ and 30 to $70 \%$, respectively, to encourage bone ingrowth. ${ }^{38}$ It was reported that human trabecular bone has a porosity of 50 to $90 \%$ and pore diameters close to $1 \mathrm{~mm} .{ }^{39}$ In view of these considerations, in the present study, HA $/ \beta$-TCP scaffolds with macropore size of $500 \mu \mathrm{m}$ and $P_{\text {macro }}$ of $0 \%, 30 \%$, and $50 \%$ were prepared by $3 \mathrm{D}$ printing.

\section{Effect of composition and $\boldsymbol{P}_{\text {macro }}$ on CS values and elastic modulus}

Composition and $P_{\text {macro }}$ are two critical factors that can affect the mechanical characteristics of $3 \mathrm{D}$ printed HA/ $\beta$-TCP scaffolds. ${ }^{16,27,29}$ In this study, the CS values were significantly affected by composition and $P_{\text {macro }}$, which showed an interactive effect. Except those of pure HA, pure $\beta$-TCP and HA wt $\%$ of $20 \%$ scaffolds, the CS values of other scaffolds were in the range of human cancellous bone ( 2 to $20 \mathrm{MPa}),{ }^{40}$ which makes these scaffolds suitable as onlay grafts for non-load-bearing applications. The results showed that with HA wt\% increased, the CS values firstly increased and then decreased, which was in accordance with Guo's reports, ${ }^{19}$ but inconsistent with what was reported previously. ${ }^{27}$ Our study showed that for scaffolds of a given $P_{\text {macro, }}$, there were no significant differences among the CS values of BCPs scaffolds with HA wt $\%$ of $40 \%, 60 \%, 80 \%$. It might because there was no significant differences among the $P_{\text {total }}$ of BCPs scaffolds with HA wt $\%$ of $40 \%, 60 \%, 80 \%$, respectively. Results of Castilho et al. indicated that the CS value increased with rising $\beta$-TCP content. ${ }^{27}$ This might mainly because the HA/ $\beta$-TCP scaffolds they used were all dense ones. On the contrary, it was reported that pure HA or TCP scaffolds showed better mechanical properties than BCPs, ${ }^{22}$ resulting from better sinterization processes. Therefore, factors like the starting powder properties, binders and sinterization processes applied had to be considered in the CS values of $3 \mathrm{D}$ printed HA/ $\beta$-TCP scaffolds. ${ }^{22,41}$

The elastic modulus of scaffolds was in the range of $0.20 \pm$ 0.02 to $1.84 \pm 0.04 \mathrm{GPa}$, which is significantly different from what was reported previously. ${ }^{41}$ The different printing powders and the design of scaffold may lead to the considerable difference. We found that for scaffolds of a given $P_{\text {macro }}$, there were no significant differences among scaffolds with various HA wt\%. Moreover, we found that for scaffolds of a given HA wt $\%$, the lower the $P_{\text {macro }}$ was, the higher the elastic modulus was, which was in accordance with the previous study. ${ }^{\mathbf{1 1}}$ Besides the individual effect that the composition and the $P_{\text {macro }}$ exert on elastic modulus, their interactions also play a major role in determining elastic modulus. The factorial analysis indicated that an 
interactive effect on elastic modulus existed between the composition and the $P_{\text {macro }}$ of the scaffolds. The results showed that scaffold with $\mathrm{HA}$ wt $\%$ of $60 \%$ and $P_{\text {macro }}$ of $0 \%$ had the highest elastic modulus among all the scaffolds.

\section{Effect of composition and $\boldsymbol{P}_{\text {macro }}$ on degradation in vitro}

Biodegradability is an important requirement for a would-be bone scaffold. ${ }^{9}$ We found that both the composition and the $P_{\text {macro }}$ play critical roles in the degradation of the HA/ $\beta$-TCP scaffolds. With increasing HA wt $\%$ in the scaffolds the degradation decreased, which was in agreement with the previous report. $^{42}$ The degradation of the pure HA scaffolds showed significant difference from that of the pure $\beta$-TCP scaffolds, and the degradation of BCPs was adjusted by altering the HA wt\%. For scaffolds of a given HA wt\%, the higher the $P_{\text {macro }}$ was, the faster the scaffolds degraded. It is acknowledged that the degradation can be promoted with higher $P_{\text {macro, }}$ which provides more spaces or channels for the circulation of fluids. ${ }^{19}$ Upon these results, it was predictable that the scaffolds could degrade more with prolonging the immersion time.

After soaking in SBF, HCA was observed in the XRD patterns of HA/ $\beta$-TCP scaffolds. In the SBF solution, series of ion exchange, dissolution and precipitation were occurred. The reason might be that calcium, phosphorus, carbonate ion and other metal ions co-exist in the SBF solution. Among the ions, calcium and phosphorus ions have nucleating effect, carbonate ion and other metal ions could deposit into the crystal lattice, thus biomineralized HCA structure was formed. HCA has the similar composition and structure with bone apatite. HCA can be easily recognized by endogenous growth factors, proteins and osteoblasts, and is beneficial to new bone formation.

In the present study, the in vitro degradation of the scaffolds was evaluated. However, the soaking time is not long enough to confirm the long-term effect of composition and $P_{\text {macro }}$ on degradation. Moreover, with respect to the in vivo degradation of the scaffolds, the phagocytosis by osteoclasts and macrophages should be taken into account, ${ }^{\mathbf{4 3}}$ in addition to the degradation through body fluid. Therefore, further study is needed to evaluate whether the in vivo degradation of the scaffolds matches the biological process of osteogenesis.

\section{Effect of composition and $\boldsymbol{P}_{\text {macro }}$ on seeding efficiency and cell attachment}

The seeding efficiency was evaluated $12 \mathrm{~h}$ after cells were seeded on the scaffolds. The 24-well plates were non-tissue culture treated to diminish adhesion and proliferation of cells in the wells. Therefore, the cells proliferation in the wells in the initial $12 \mathrm{~h}$ was very low. The influence of cell proliferation in the well on the seeding efficiency values during the $12 \mathrm{~h}$ could be neglected. ${ }^{41}$ The seeding efficiency of the $3 \mathrm{D}$ printed HA/ $\beta$-TCP scaffolds varied in the range of 73.00 to $96.33 \%$. However, in one study, the seeding efficiency of 3D printed scaffold with pore size of $750 \mu \mathrm{m}$ was approximately $30 \% .{ }^{41}$ It can be explained that the material they used to fabricate the scaffold was a blend of corn starch with poly( $\varepsilon$-caprolactone), which can reduce cell attachment and proliferation.
For scaffolds of a given $P_{\text {macro, }}$, we found that the seeding efficiency of scaffolds with $\mathrm{HA}$ wt $\%$ of $60 \%$ was higher than those of pure HA or pure $\beta$-TCP, respectively, while the seeding efficiency of various BCPs showed no significant differences. In addition, we found that the seeding efficiency increased as the $P_{\text {macro }}$ increased. The higher the $P_{\text {macro }}$ is, the more the interconnection sites exist in scaffold. The higher number of interconnection sites in scaffold might contribute to higher cell seeding efficiency. Since the existence of more interconnection points might be related to better anchorage of cells to the scaffolds, increasing the chances of cell adhesion upon seeding. The SEM images, showing BMSCs attached and spread on HA/ $\beta$-TCP scaffolds, further confirmed the good biocompatibility of the scaffolds.

In addition to the individual effect that the composition and the $P_{\text {macro }}$ exert on seeding efficiency, an interactive effect between the composition and the $P_{\text {macro }}$ of the scaffolds existed. Within the study ranges, the highest seeding efficiency was obtained on scaffolds with HA wt $\%$ of $40 \%$ and $P_{\text {macro }}$ of $50 \%$.

\section{Effect of composition and $\boldsymbol{P}_{\text {macro }}$ on cell proliferation}

Cell proliferation was monitored using CCK-8 on Day 1, Day 4, and Day 7. The ANOVA analysis showed that the cell proliferation on each scaffold was significantly higher with the time prolonged. For scaffolds of a given $P_{\text {macro }}$, on Day 1 and Day 7, significantly higher proliferation was detected on scaffolds with HA wt $\%$ of $40 \%, 60 \%$ and $80 \%$ than those on pure HA scaffolds. On Day 1 and Day 4, significantly higher proliferation was detected on scaffolds with HA wt $\%$ of $40 \%$ than those on pure $\beta$-TCP scaffolds. On Day 1, Day 4, and Day 7, cells on BCPs showed an enhanced proliferation in comparison to those on pure HA or pure $\beta$-TCP scaffolds. However, cell proliferation among various BCPs showed no significant differences at each time point. The statistical analyses revealed that composition can significantly affect the cell proliferation, however, the exact HA wt\% is not critical. These results were in consistent with previous studies. ${ }^{\mathbf{1 2 1 4 , 2 7}}$ They showed that BCPs exerted better cytocompatibility and the ability of promoting osteogenesis than pure HA or pure $\beta$-TCP scaffolds. However, the results were in disagreement with the reports by Detsch $\mathrm{R}$ et al. ${ }^{29}$ They seeded osteoclastic cells on 3D printed pure HA, pure $\beta$-TCP and various BCPs scaffolds. After 21 days of cultivation, cell viability and proliferation was measured. It was showed that cell viability and proliferation was nearly the same on all the scaffolds. On the one hand, this might due to the much longer time they used to culture the cells. On the other hand, the interaction of the calcium phosphate scaffolds with different cell types might be different.

For scaffolds of a given HA wt\%, the higher the $P_{\text {macro }}$ was, the higher the cell proliferation was. It can be explained that larger porosity enables cells to proliferate better resulting from larger space and better supply of oxygen and nutrients. The results showed that the cell proliferation were significantly different among scaffolds with different $P_{\text {macro }}$ at each time point, except that of scaffolds with $P_{\text {macro }}$ of $30 \%$ and $50 \%$ on Day 1. This might because the cells mainly attached to the 
scaffolds, and proliferated less on Day 1. Though macropores were important for fluid exchange and cell migration, ${ }^{37}$ the influence of $P_{\text {macro }}$ was not obvious for scaffolds with $P_{\text {macro }}$ of $30 \%$ and $50 \%$ on Day 1 . The cell proliferation on each scaffold was lower than that of the negative control group on Day 1, Day 4 , and Day 7, respectively. This might result from the relatively fewer cells on the scaffolds compared to cells of the negative control group.

Besides the individual effect that the composition and the $P_{\text {macro }}$ exert on cell proliferation, their interactions also play a major role in determining the outcome parameters of cell proliferation. The factorial analysis indicated that an interactive effect on cell proliferation existed between the composition and the $P_{\text {macro }}$ of the scaffolds. The results demonstrated that scaffold with $\mathrm{HA}$ wt $\%$ of $40 \%$ and $P_{\text {macro }}$ of $50 \%$ had no significant difference with the control group for cell proliferation.

\section{Effect of composition and $\boldsymbol{P}_{\text {macro }}$ on osteogenic differentiation}

ALP is generally regarded as an early marker for osteogenic differentiation. It was found that ALP expression peaked at the early stage of osteoblastic differentiation and then declined as differentiation progresses. ${ }^{44}$ RUNX-2 is among the first genes expressed in the early process of calcification as well. ${ }^{45}$ OCN, secreted by osteoblast, is the most abundant non-collagenous protein of bone, which signals terminal osteoblast differentiation. ${ }^{46}$ Therefore, cell osteogenic differentiation capacity was analyzed by assessing mRNA expressions of these typical osteogenic markers.

The ALP, RUNX-2 and OCN mRNA were expressed on all the scaffolds, which indicated the osteogenic differentiation and confirmed the good biocompatibility of the scaffolds. The statistical analyses showed that both the composition and the $P_{\text {macro }}$ significantly affected the ALP, RUNX-2 and OCN mRNA expressions. In addition, the composition and the $P_{\text {macro }}$ exhibited an interactive effect on ALP and RUNX-2 mRNA expression. The results of our study showed that ALP, RUNX-2 and OCN mRNA expressions on scaffold with HA wt\% of $60 \%$ were significantly higher than those on pure $\beta$-TCP, respectively. This might partly due to the degradation rate and the degradation products of scaffold with $\mathrm{HA} w \mathrm{wt} \%$ of $60 \%$ are different from those of the pure $\beta$-TCP scaffold. For scaffolds of a given HA wt\%, ALP, RUNX-2 and OCN mRNA expressions on scaffold with $P_{\text {macro }}$ of $0 \%$ were significantly higher than those on scaffold with $P_{\text {macro }}$ of $50 \%$, respectively. Moreover, RUNX-2 mRNA expression on scaffolds with $P_{\text {macro }}$ of $30 \%$ was significantly higher than that on scaffold with $P_{\text {macro }}$ of $50 \%$. This was in accordance with the report of Karageorgiou and Kaplan that lower porosity enhances osteogenic differentiation by suppressing cell proliferation and forcing cell aggregation in vitro. ${ }^{37}$ The RUNX-2 and OCN mRNA expressions were lower than ALP mRNA expression in the control group. This might because the ALP, RUNX-2 and OCN expressed at different stages of osteogenic differentiation. ${ }^{\mathbf{4 4 , 4 6}}$

In comparison with those of the control group, ALP and RUNX-2 mRNA expressions on scaffolds were lower, respectively. However, the OCN mRNA expression on the scaffold with
HA wt $\%$ of $60 \%$ and $P_{\text {macro }}$ of $0 \%$ was significantly higher than that of the control group. The results suggested that scaffolds cultured with cells decreased both ALP and RUNX-2 mRNA expressions, but to some extent, increased OCN mRNA expression. Besides the reason of seeding efficiency, this might be relevant with the levels of degradation products in the culture microenvironment, which needs further in-depth investigation. However, with respect to ALP and RUNX-2 mRNA expressions, scaffold with $\mathrm{HA}$ wt $\%$ of $60 \%$ and $P_{\text {macro }}$ of $30 \%$ showed no significant differences with those of the control group, respectively. With regards to OCN mRNA expression, there were no significant differences among scaffolds with HA wt\% of $40 \%$, $80 \%$, and $P_{\text {macro }}$ of $0 \%$ and the control group, respectively. Moreover, OCN mRNA expression on scaffolds with HA wt $\%$ of $60 \%$ and $P_{\text {macro }}$ of $0 \%$ and $30 \%$, with that of the control group showed no significant differences, respectively. Taken together, the results suggested that scaffold with $\mathrm{HA} \mathrm{wt} \%$ of $60 \%$ and $P_{\text {macro }}$ of $30 \%$ had no significant difference with the control group for osteogenic differentiation.

\section{Conclusions}

The CS values, degradation behavior and biocompatibility of the scaffolds significantly depended on both the composition and the $P_{\text {macro, }}$, which exhibited an interactive effect. With a comprehensive analysis, it is demonstrated that BCPs showed higher CS value, seeding efficiency, cell proliferation and differentiation capability in comparison with pure HA or pure $\beta$-TCP scaffold. In addition, with regards to CS values, seeding efficiency, cell proliferation and RUNX-2 and OCN mRNA expressions, there were no significant differences among various BCPs. The in vitro degradation of HA/ $\beta$-TCP scaffolds decreased as the HA wt\% increased. The higher the $P_{\text {macro }}$ was, the higher the degradation was. In comparison with the control group, scaffold with $\mathrm{HA}$ wt\% of $40 \%$ and $P_{\text {macro }}$ of $50 \%$ exhibited no significant difference for cell proliferation. Scaffold with HA wt $\%$ of $60 \%$ and $P_{\text {macro }}$ of $30 \%$ had no significant difference for osteogenic differentiation. Within the limits of this study, the results provide useful in vitro information in understanding the mechanical properties and biocompatibility of 3D printed HA/ $\beta$-TCP scaffolds for restoring and augmenting the absorbed alveolar ridge. Additional studies are underway to further evaluate the biocompatibility and bone formation capacity of $3 \mathrm{D}$ printed HA/ $\beta$-TCP scaffolds in vivo.

\section{Conflicts of interest}

The authors declare that they have no conflicts of interest with the contents of this article.

\section{Acknowledgements}

We thank Professor John Donohoe and Dr Shaoyong Xu for their editorial assistance in the preparation of this manuscript. We express our thanks to Professor Yingying Wang for the critical reading of this manuscript. We thank Dr Xinpei Li for the support in figure processing. 


\section{Notes and references}

1 R. E. Jung, G. I. Benic, D. Scherrer and C. H. Hammerle, Clin. Oral Implants Res., 2015, 26, 28-34.

2 F. Fontana, E. Maschera, I. Rocchietta and M. Simion, Int. J. Periodontics Restorative Dent., 2011, 31, 265-273.

3 M. Padial-Molina, F. O'Valle, A. Lanis, F. Mesa, D. M. Dohan Ehrenfest, H. L. Wang and P. Galindo-Moreno, BioMed Res. Int., 2015, 2015, 341327.

4 F. P. Sehn, R. R. Dias, T. de Santana Santos, E. R. Silva, L. A. Salata, G. Chaushu and S. P. Xavier, J. Biomater. Appl., 2015, 29, 1003-1013.

5 J. C. da Rosa, A. C. Rosa, M. A. Fadanelli and B. S. SottoMaior, J. Prosthet. Dent., 2014, 112, 717-722.

6 M. Tosta, A. R. Cortes, L. Correa, S. Pinto Ddos Jr, I. Tumenas and E. Katchburian, Clin. Oral Implants Res., 2013, 24, 866870.

7 R. Bettach, B. Guillaume, S. Taschieri and M. Del Fabbro, Implant Dent., 2014, 23, 357-364.

8 F.-M. Chen and X. Liu, Prog. Polym. Sci., 2016, 53, 86-168.

9 S. Bose, M. Roy and A. Bandyopadhyay, Trends Biotechnol., 2012, 30, 546-554.

10 Y. Hong, A. Huber, K. Takanari, N. J. Amoroso, R. Hashizume, S. F. Badylak and W. R. Wagner, Biomaterials, 2011, 32, 3387-3394.

11 S. A. Poursamar, A. N. Lehner, M. Azami, S. EbrahimiBarough, A. Samadikuchaksaraei and A. P. Antunes, Mater. Sci. Eng., C, 2016, 63, 1-9.

12 D. T. Nguyen, J. D. McCanless, M. M. Mecwan, A. P. Noblett, W. O. Haggard, R. A. Smith and J. D. Bumgardner, J. Biomater. Sci., Polym. Ed., 2013, 24, 1071-1083.

13 D. W. Hutmacher, Biomaterials, 2000, 21, 2529-2543.

14 S. Chen, Z. He, G. Xu and X. Xiao, J. Biomater. Sci., Polym. Ed., 2016, 27, 1058-1068.

15 B. C. Gross, J. L. Erkal, S. Y. Lockwood, C. Chen and D. M. Spence, Anal. Chem., 2014, 86, 3240-3253.

16 M. Schumacher, U. Deisinger, R. Detsch and G. Ziegler, J. Mater. Sci.: Mater. Med., 2010, 21, 3119-3127.

17 Y.-J. Seol, T.-Y. Kang and D.-W. Cho, Soft Matter, 2012, 8, 1730-1735.

18 G. A. Fielding, A. Bandyopadhyay and S. Bose, Dent. Mater., 2012, 28, 113-122.

19 D. Guo, K. Xu and Y. Han, J. Biomed. Mater. Res., Part A, 2009, 88, 43-52.

20 Y. J. Seol, D. Y. Park, J. Y. Park, S. W. Kim, S. J. Park and D. W. Cho, Biotechnol. Bioeng., 2013, 110, 1444-1455.

21 A. Butscher, M. Bohner, S. Hofmann, L. Gauckler and R. Muller, Acta Biomater., 2011, 7, 907-920.

22 D. O. Costa, P. D. Prowse, T. Chrones, S. M. Sims, D. W. Hamilton, A. S. Rizkalla and S. J. Dixon, Biomaterials, 2013, 34, 7215-7226.

23 M. Stiller, E. Kluk, M. Bohner, M. A. Lopez-Heredia, C. Muller-Mai and C. Knabe, Biomaterials, 2014, 35, 31543163.
24 G. Y. Jung, Y. J. Park and J. S. Han, J. Mater. Sci.: Mater. Med., 2010, 21, 1649-1654.

25 S. V. Dorozhkin, Acta Biomater., 2012, 8, 963-977.

26 A. L. Gamblin, M. A. Brennan, A. Renaud, H. Yagita, F. Lezot, D. Heymann, V. Trichet and P. Layrolle, Biomaterials, 2014, 35, 9660-9667.

27 M. Castilho, C. Moseke, A. Ewald, U. Gbureck, J. Groll, I. Pires, J. Tessmar and E. Vorndran, Biofabrication, 2014, 6, 015006.

28 S. N. Rath, L. A. Strobel, A. Arkudas, J. P. Beier, A. K. Maier, P. Greil, R. E. Horch and U. Kneser, J. Cell. Mol. Med., 2012, 16, 2350-2361.

29 R. Detsch, S. Schaefer, U. Deisinger, G. Ziegler, H. Seitz and B. Leukers, J. Biomater. Appl., 2011, 3, 359-380.

30 P. Habibovic, H. Yuan, C. M. van der Valk, G. Meijer, C. A. van Blitterswijk and K. de Groot, Biomaterials, 2005, 26, 3565-3575.

31 J. Will, R. Melcher, C. Treul, N. Travitzky, U. Kneser, E. Polykandriotis, R. Horch and P. Greil, J. Mater. Sci.: Mater. Med., 2008, 19, 2781-2790.

32 N. Mardas, V. Chadha and N. Donos, Clinical oral implants research, 2010, 21, 688-698.

33 A. Bandyopadhyay and S. Bose, Characterization of biomaterials, Newnes, 2013.

34 A. Bignon, J. Chouteau, J. Chevalier, G. Fantozzi, J. P. Carret, P. Chavassieux, G. Boivin, M. Melin and D. Hartmann, J. Mater. Sci.: Mater. Med., 2003, 14, 1089-1097.

35 B. S. Chang, C. K. Lee, K. S. Hong, H. J. Youn, H. S. Ryu, S. S. Chung and K. W. Park, Biomaterials, 2000, 21, 12911298.

36 C. M. Murphy, M. G. Haugh and F. J. O'Brien, Biomaterials, 2010, 31, 461-466.

37 V. Karageorgiou and D. Kaplan, Biomaterials, 2005, 26, 54745491.

38 A. Curodeau, E. Sachs and S. Caldarise, J. Biomed. Mater. Res., 2000, 53, 525-535.

39 T. M. Keaveny, E. F. Morgan, G. L. Niebur and O. C. Yeh, Annu. Rev. Biomed. Eng., 2001, 3, 307-333.

40 M. J. Olszta, X. Cheng, S. S. Jee, R. Kumar, Y.-Y. Kim, M. J. Kaufman, E. P. Douglas and L. B. Gower, Mater. Sci. Eng., $R$, 2007, 58, 77-116.

41 J. M. Sobral, S. G. Caridade, R. A. Sousa, J. F. Mano and R. L. Reis, Acta Biomater., 2011, 7, 1009-1018.

42 R. Z. LeGeros, Chem. Rev., 2008, 108, 4742-4753.

43 D. F. Duarte Campos, M. Vogt, M. Lindner, A. Kirsten, M. Weber, R. T. Megens, J. Pyta, M. Zenke, M. Van Zandvoort and H. Fischer, Microsc. Res. Tech., 2014, 77, 143-152.

44 B. M. Whited, J. R. Whitney, M. C. Hofmann, Y. Xu and M. N. Rylander, Biomaterials, 2011, 32, 2294-2304.

45 D. Agas, M. G. Sabbieti, L. Marchetti, L. Xiao and M. M. Hurley, J. Cell. Physiol., 2013, 228, 2149-2158.

46 P. V. Hauschka, J. B. Lian, D. E. Cole and C. M. Gundberg, Physiol. Rev., 1989, 69, 990-1047. 